\title{
Identification of BMP2 as an epigenetically silenced growth inhibitor in rhabdomyosarcoma
}

\author{
SEBASTIAN WOLF, BEATE HAGL and ROLAND KAPPLER \\ Department of Pediatric Surgery, Dr. von Hauner Children's Hospital, \\ Ludwig-Maximilians-University Munich, D-80337 Munich, Germany
}

Received December 18, 2013; Accepted February 6, 2014

DOI: $10.3892 /$ ijo.2014.2312

\begin{abstract}
Rhabdomyosarcoma (RMS) is the most common soft-tissue sarcoma of infancy and although therapy has improved over the years, mortality is still fairly high. The establishment of new treatments has been hampered by the limited knowledge of the molecular mechanisms driving development of RMS. One characteristic of cancer cells is aberrant DNA methylation, which could lead to silencing of tumor suppressor genes. However, only a few epigenetically silenced genes have been described in RMS so far. We performed an expression profiling analysis of three RMS cell lines that were treated with the demethylating agent 5'-aza-2'-deoxycytidine (5-Aza-dC) facilitating re-expression of epigenetically silenced genes. This treatment induced the gene BMP2 (bone morphogenetic protein 2) throughout all cell lines. Detailed methylation analysis of $\mathrm{CpG}$ sites in the $B M P 2$ promoter region by bisulfite sequencing and methylation-specific PCR revealed that a high degree of DNA methylation is causatively associated with the suppression of BMP2 in RMS cells. Consequently, treatment of the RMS cell lines with 5-Aza-dC resulted in DNA demethylation of the $B M P 2$ promoter, most prominently in alveolar RMS. Supplementation of recombinant human BMP2 (rhBMP2) led to a reduced viability of RMS cells. Altogether, these findings suggest that suppression of BMP2 by epigenetic silencing may play a critical role in the genesis of RMS, thereby providing a rationale for the development of a new treatment strategy for RMS.
\end{abstract}

\section{Introduction}

Rhabdomyosarcoma (RMS) is the most common soft-tissue sarcoma of infancy with an incidence of approximately

Correspondence to: Dr Roland Kappler, Department of Pediatric Surgery, Dr. von Hauner Children's Hospital, Ludwig-MaximiliansUniversity Munich, Lindwurmstr. 2a, D-80337 Munich, Germany E-mail: roland.kappler@med.uni-muenchen.de

Key words: bone morphogenetic protein 2, methylation, rhabdomyosarcoma, promoter, expression
4-7 cases per million children (1). As RMS can arise from any striated muscle in the body, the localization is very diverse. The most common site of origin is the head and neck region (35\%), but also the genitourinary tract $(24 \%)$ and the extremities $(20 \%)$ are favoured afflicted spots (2). Histologically, RMS can be divided into two major subtypes. Embryonal RMS is the most common variant and is characterized by an early onset in children $<10$ years of age (3). Because of a fairly low tendency of metastasis, its prognosis, especially of the botryoid variant, is quite good (4). On the other hand, there is the alveolar RMS known as the second most common RMS subtype (3). Typical features of this subtype are a later onset, mainly in adolescence, the localization in extremities, and a worse prognosis, because of rapid metastasis and poor response to treatment (5). The RMS subtypes are also distinguishable on the molecular level. Embryonal RMS are commonly characterized by loss of heterozygosity of the chromosomal region 11p15, which affects the locus of the insulin-like growth factor II (IGF2) gene and leads to its overexpression (6). Alveolar RMS can bear two typical reciprocal translocations, one between chromosome 1 and $13(\mathrm{t}(1 ; 13)(\mathrm{p} 36 ; \mathrm{q} 14))$, the other between chromosome 2 and 13 (t(2;13)(p35; 14$))$. This can fuse the $P A X 3$ or the $P A X 7$ gene with the $F K H R$ gene, which subsequently results in abnormal activation of target genes and oncogenic deregulation $(7,8)$.

Currently, epigenetic alterations are discussed as an important element in the regulation of various factors implicated in tumor development. One of the most common molecular features of cancer cells is aberrant DNA methylation of usually unmethylated $\mathrm{CpG}$ islands located in the promoter regions of tumor suppressor genes, which could lead to their transcriptional suppression (9). Although a whole plethora of epigenetically silenced genes has been described for most cancers, the methylation status of RMS is still fairly unknown. One of the few genes investigated in this tumor is Ras association (RalGDS/AF-6) domain family member 1 (RASSF1A) (10). The epigenetic downregulation of RASSF1A is a common phenomenon in a variety of childhood cancers and associated with poorer prognosis in some of them $(11,12)$. Nevertheless, because of the important link between promoter methylation and the development and progression of cancer the identification of epigenetically regulated genes in RMS is of utmost importance.

A candidate gene for epigenetic regulation encodes the bone morphogenetic protein 2 (BMP2), which belongs to the 
transforming growth factor $\beta$ superfamily. Although BMP2 was first described as an initiator of enchondral bone formation (13), its function is way more comprehensive playing important roles in embryonic development during the formation and differentiation of various organs (14-16). BMPs act via activation of transmembrane serine/threonine-kinase-receptors, which are composed of type I and type II subunits, namely BMPR1A, BMPR1B and BMPR2 (17). This heterodimerization leads to phosphorylation and grouping of SMAD proteins and their translocation to the nucleus. After binding to specific DNA-sequences, several target genes, such as ID1-3 (inhibitor of DNA binding protein 1-3) are either going to be activated or repressed (18). Besides these physiological mechanisms of action, $B M P 2$ is also involved in tumorigenesis. There is growing evidence that suggests $B M P 2$ as an important tumor suppressor gene. It was shown that different tumors often feature a genetic loss of $B M P 2$ expression (19). Reconstitution of BMP2 function through recombinant BMP2 treatment resulted in a reduced growth and even partially increased apoptosis rate of tumor cells, as described for prostate carcinoma, medulloblastoma, and myeloma (20-22).

Here, we aimed at identifying epigenetically silenced genes in RMS in order to further the understanding of tumor development and progression. Our finding that $B M P 2$ is heavily methylated and the gene thus transcriptionally inactive in RMS cell lines along with the anti-proliferative effect mediated by BMP2 reconstitution in vitro suggests a strong tumor suppressive role of this protein, which might be of use to develop future treatment options.

\section{Materials and methods}

Tumor cell lines. We used the three different RMS cell lines RD (embryonal RMS, ATCC, Manassas, VA, USA), RH30 (alveolar RMS, DSMZ, Braunschweig, Germany), and RMS13 (alveolar RMS, ATCC). The embryonal RUCH2 as well as the alveolar RH4 and RH18 cell lines were generously provided by Dr Beat Schäfer. All cell lines were maintained as the suppliers recommended.

Real-time reverse transcription polymerase chain reaction $(R T-P C R)$. Total RNA was extracted from fresh-frozen healthy muscle tissue and RMS cell lines in TRI Reagent ${ }^{\circledR}$ RNA isolation reagent (Molecular Research Center, Cincinnati, $\mathrm{OH}$, USA). Total RNA was depleted from DNA and subsequently purified using RNeasy Mini Kit in combination with DNase set (Qiagen, Hilden, Germany). Reverse transcription of total RNA was performed using random hexamers (Roche Diagnostics, Penzberg, Germany) and SuperScript ${ }^{\circledR}$ II reverse transcriptase (Invitrogen, Karlsruhe, Germany). RT-PCR amplifications of the selected genes were carried out with $40 \mathrm{ng}$ complementary DNA, $10 \mu \mathrm{M}$ forward and reverse primer, and 2X iTaq SYBR-Green Supermix with ROX (Bio-Rad Laboratories $\mathrm{GmbH}$, München, Germany) in a final volume of $20 \mu$ l. RT-PCR reactions started with a primary denaturation for $2 \mathrm{~min}$ at $95^{\circ} \mathrm{C}$ and thereupon were run for 40 cycles consisting of 15 -sec denaturation at $95^{\circ} \mathrm{C}$, primer annealing for $15 \mathrm{sec}$ at $55^{\circ} \mathrm{C}$, and extension for $20 \mathrm{sec}$ at $68^{\circ} \mathrm{C}$. We used the following primer pairs $\left(5^{\prime} \rightarrow 3^{\prime}\right.$ orientation): $B M P 2$, CAGCCAG CCGAGCCAA, AATCTCCGGGTTGTTTTCCC; BMPRlA,
CTACCAAACTGTGCTAATGCGC, CAAATAGAGCTGAG TCCAGGAACC; BMPRIB, CCATTGTCCAGAAGACTC AGTCAA, CACAGGCAACCCAGAGTCATC; BMPR2, TGGACGCATGGAATATTTGC, GCTTACCCAGTCACTT GTGTGG; $C D K N 1 A$, AGGCTGAAGGGTCCCCAG, CGGC GTTTGGAGTGGTAGAA; $C D K N 2 A$, AGGCAGTAACCA TGCCCG, TTCCCGAGGTTTCTCAGAGC; $C D K N 2 B$, AGCTGAGCCCAGGTCTCCTAG, CACCGTTGGCCGTAA ACTTAAC; IDI, AACGGCTGTTACTCACGCCT, CGATGA CGTGCTGGAGAATCT; ID3, CCTGGACCCCCTGATGG, GGCAAAAGCTCCTTTTGTCGT; RASSF1A, GGCGTCG TGCGCAAA, GATCTTCTGCTCAATCTCAGCTTG; TBP, GCCCGAAACGCCGAATAT, CCGTGGTTCGTGGCTC TCT. Primer sequences of the 92-gene screening approach are available upon request. RT-PCR amplifications were performed on a Mastercycler ep realplex ${ }^{2} \mathrm{~S}$ (Eppendorf, Hamburg, Germany) and all experiments were performed in doublets. Amplification of the housekeeping gene TATA-box-bindingprotein $(T B P)$ was performed to standardize the amount of sample RNA. Relative quantification of gene expression was performed using the $\Delta \Delta$ ct method as described earlier (23).

Methylation analyses. Genomic DNA of RMS cell lines was extracted with phenol and chloroform, ethanol precipitated and dissolved in TE buffer following standard procedures. In order to get fully methylated DNA as a positive control for methylation analyses, $10 \mu \mathrm{g}$ genomic DNA extracted from blood of a healthy individual was incubated with $\mathrm{CpG}$ methyltransferase M. SssI (4 U/ $\mu 1$, New England Biolabs, Frankfurt, Germany) in 10X NE buffer 2 and SAM (1:20) for $4 \mathrm{~h}$ at $37^{\circ} \mathrm{C}$. After enzyme inactivation at $65^{\circ} \mathrm{C}$, DNA was precipitated with $0.3 \mu \mathrm{M}$ sodium acetate and $100 \%$ ethanol. Genomic DNA was bisulfite-treated using EpiTect ${ }^{\circledR}$ Bisulfite Kit (Qiagen GmbH).

For bisulfite sequencing, we amplified bisulfite-modified genomic DNA by using primers not specific for methylation status (BMP2-BS-fw, CAAAGGGCACTTGGCCCCAGGG; BMP2-BS-rev, CAAGTTATTCTCCCTGCAAGTTCA). We cloned the PCR products into the pCR2.1 vector and transformed them into TOP10F' (both from Invitrogen). After the preparation of plasmid DNA by the use of Qiagen plasmid mini kit (Qiagen), the clones were sent for sequencing (MWG Biotech, Ebersberg, Germany).

For methylation-specific-PCR (MSP), we used primerpairs specific for either methylated or unmethylated $\mathrm{CpGs}$ that bind to two different regions of the BMP2 promoter (Fig. 2A). The following primer sets were used $\left(5^{\prime} \rightarrow 3^{\prime}\right.$-orientation): $B M P 2$ region 1 methylated, GTAGAGCGCGTTATAGCGTC, CATC GCGACGCTAAAAAT; BMP2 region 1 unmethylated, GGT AGAGTGTGTTATAGTGTTGTGG, ACATCACAACACTA AAAATCAACTC; $B M P 2$ region 2 methylated, TGGTATCG AGATCGTCGTC, TCCGAAACTCGAAAATCG; $B M P 2$ region 2 unmethylated, GTTTGGTATTGAGATTGTTGT TGT, AACTCCAAAACTCAAAAATCA. Primer design for MSP was accomplished using Methyl Primer Express (Applied Biosystems, Foster City, CA, USA) considering the following criteria: primers cover at least three $\mathrm{CpG}$ dinucleotides in its sequence, $\mathrm{CpG}$ percentage $>55 \%$, observed/expected $\mathrm{CpG}$ $>65 \%$, and $\mathrm{CpG}$ island length between 300-2,000 bp. The MSP reaction contained $225 \mathrm{ng}$ DNA, $10 \mu \mathrm{M}$ forward and reverse primer, $10 \mathrm{mM}$ deoxyribonucleotide triphosphates, 
A

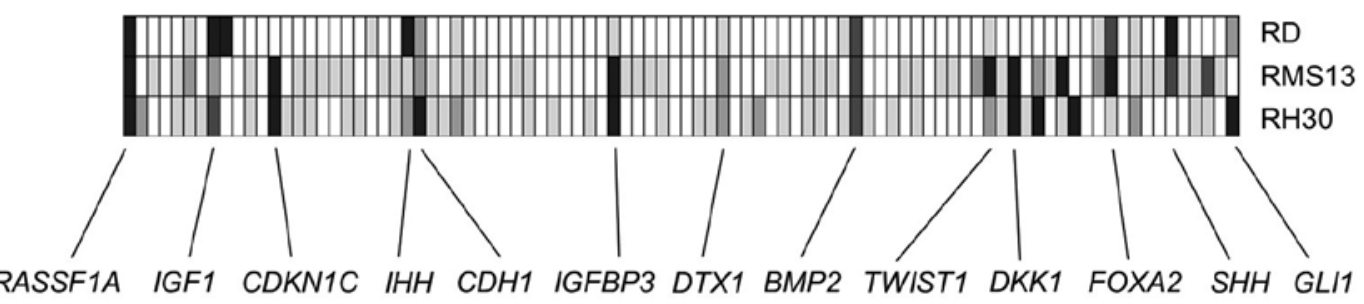

Fold-induction: \begin{tabular}{lllllll}
0 & 1 & 3 & 10 & 20 & $\infty$ \\
\hline & 1 & 1 & 1 & &
\end{tabular}

B

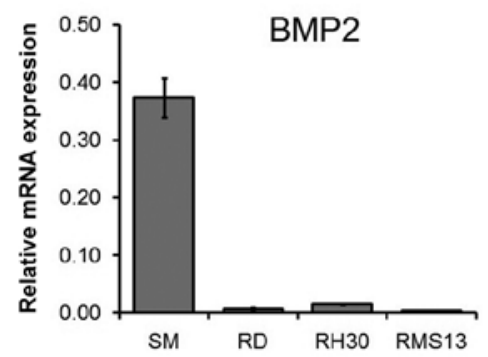

C
D

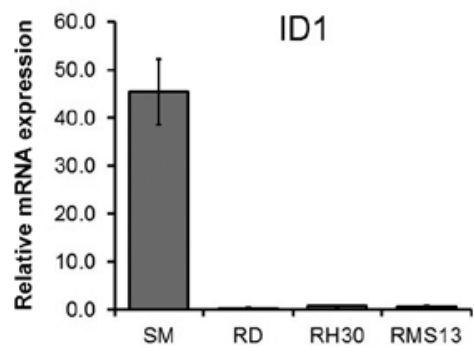

E

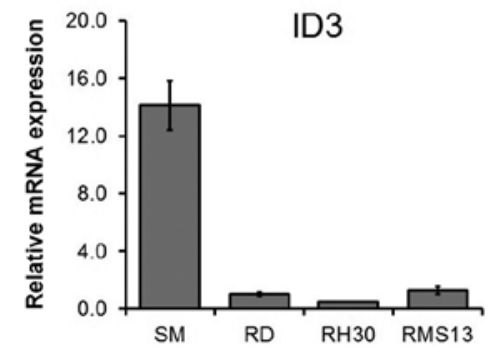

F

SM RD RH30 RMS13

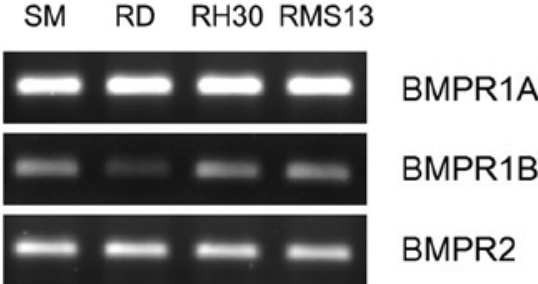

$\beta$-actin

BMP2

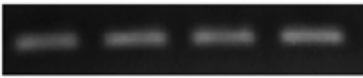

TBP

Figure 1. Identification of $B M P 2$ as an epigenetically silenced gene in RMS cell lines. (A) Schematic compilation of the results from the quantitative real-time RT-PCR-based screening assay that shows the fold-induction of the candidate genes in different RMS cell lines treated for 5 days with $5 \mu \mathrm{M} 5$-Aza-dC, as compared to untreated cells. Candidate genes with a mean induction of gene expression in all three RMS cell lines $>3$-fold are indicated. (B) Relative mRNA and (C) protein levels of $B M P 2$ in healthy skeletal muscle tissue (SM) and the RMS tumor cell lines RD, RH30 and RMS13. Immunodetection of $\beta$-actin served as a standard for equal protein loading of the gel. Relative mRNA expression of the target genes (D) IDI and (E) ID3 in SM and RMS cells in relation to the housekeeping gene TBP. (F) Representative image of the RT-PCR demonstrating the abundance of the BMP receptor genes BMPR1A, BMPR1B and BMPR2 in SM and RMS cells.

$25 \mathrm{mM} \mathrm{MgCl} 2,1 \mathrm{U}$ Hot Start Taq DNA polymerase, and 10X Hot Start PCR buffer (Fermentas, St. Leon-Rot, Germany). Conditions for MSP were $95^{\circ} \mathrm{C}$ for $4 \mathrm{~min}$, followed by 38 cycles of $94^{\circ} \mathrm{C}$ for $30 \mathrm{sec}, 60^{\circ} \mathrm{C}$ (BMP2 region 1) or $59^{\circ} \mathrm{C}$ (BMP2 region 2) for $30 \mathrm{sec}$ and $72^{\circ} \mathrm{C}$ for $45 \mathrm{sec}$, with a final extension cycle of $72^{\circ} \mathrm{C}$ for $10 \mathrm{~min}$. The PCR products were resolved by electrophoresis in a $2 \%$ agarose gel.

For DNA demethylation experiments, cells were seeded in 5 or $25 \mathrm{~cm}^{2}$ cell flasks and incubated with $1 \mu \mathrm{M} 5$-aza2'-deoxycytidine (5-Aza-dC; Sigma-Aldrich, Steinheim, Germany) for 5 days. Demethylating agent-containing media were changed every day.

Cell viability assay. For proliferation assays $5 \times 10^{3}$ cells/96-well plates were treated with recombinant human BMP2 (rhBMP2, R\&D Systems, Minneapolis, MN, USA) in concentrations of $50,75,100$, and $200 \mathrm{ng} / \mathrm{ml}$. The viability was assessed at 0, 24, 48 and $72 \mathrm{~h}$ using the Cell Proliferation Kit I (Roche Diagnostics) according to the manufacturer's protocol. Optical density was measured after the addition of 3-(4,5-dimethylthiazol-2-yl)-2,5-diphenyltetrazolium bromide (MTT) labeling reagent on the GENios microplate reader (Tecan Deutschland $\mathrm{GmbH}$, Crailsheim, Germany) at a wavelength of $595 \mathrm{~nm}$.

Apoptosis analyses. For Annexin V-based apoptosis analysis, cells were seeded in 6 -well plates $\left(5 \times 10^{5}\right.$ cells/well) and treated with $75 \mathrm{ng} / \mathrm{ml} \mathrm{rhBMP} 2$ for 24,48 and $72 \mathrm{~h}$. Thereafter, the cells were trypsinized, washed with PBS, and suspended in $500 \mu \mathrm{l}$ of calcium-containing binding buffer. Cy5-conjugated Annexin V (1:100; BioVision, Mountain View, CA, USA) and $1 \mathrm{mM}$ calcein AM (Invitrogen) were added to the cell suspension. Early apoptotic cells (Annexin V and calceinpositive) were detected using cell fluorescence assays on a 2100 Bioanalyzer (Agilent Technologies, Santa Clara, CA, USA).

Statistical analysis. Data were expressed as means plus standard deviations and statistically subjected to Student's unpaired 


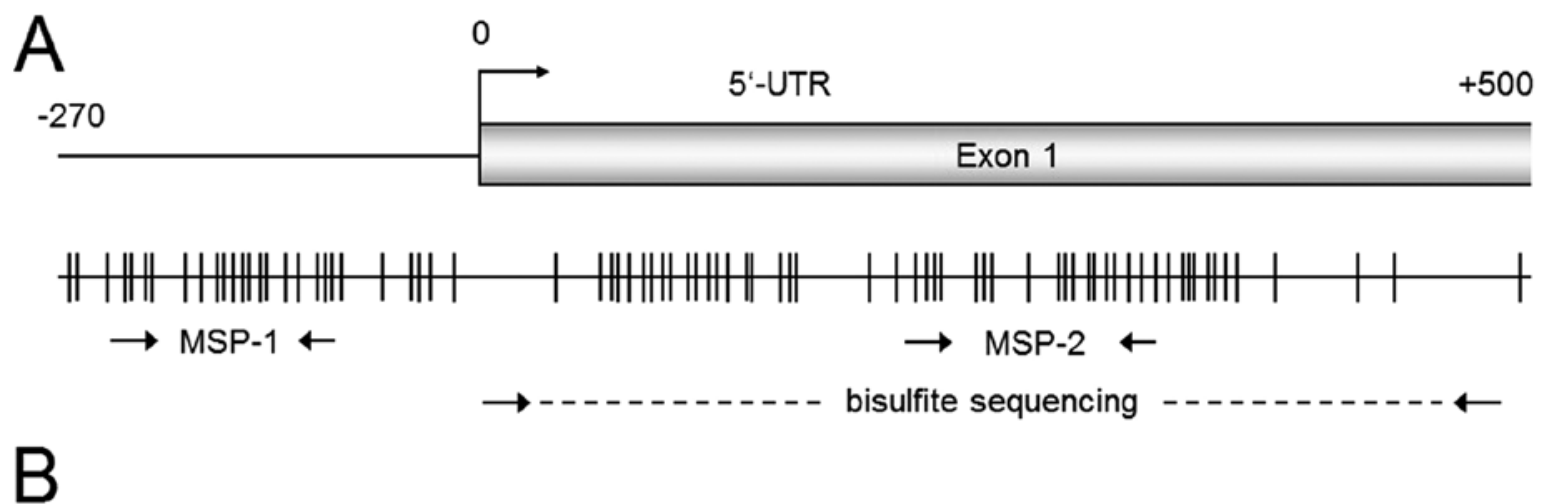

RD

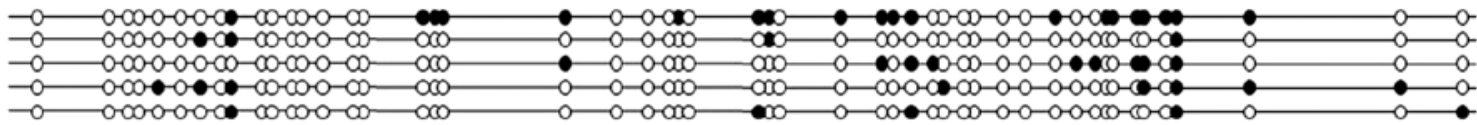

RMS-13

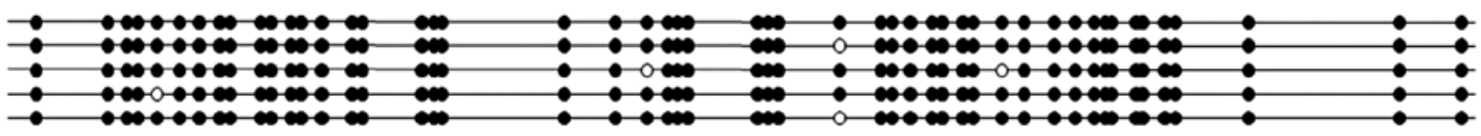

$\mathrm{RH}-30$

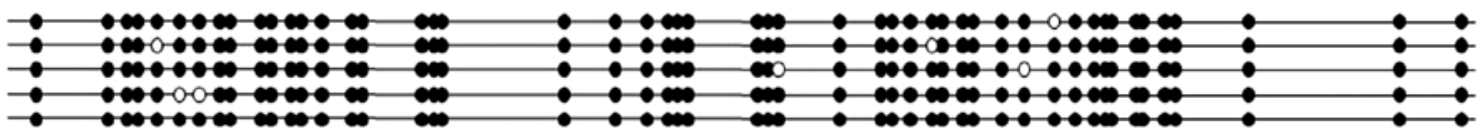

peripheral blood

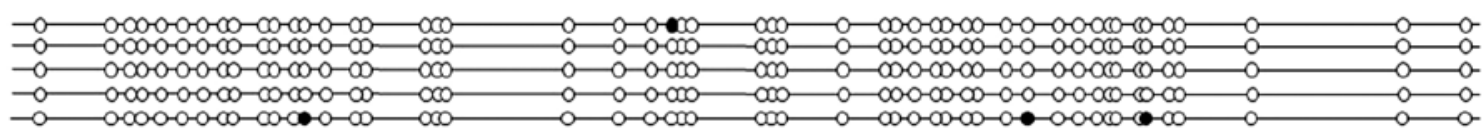

\section{SSSI}

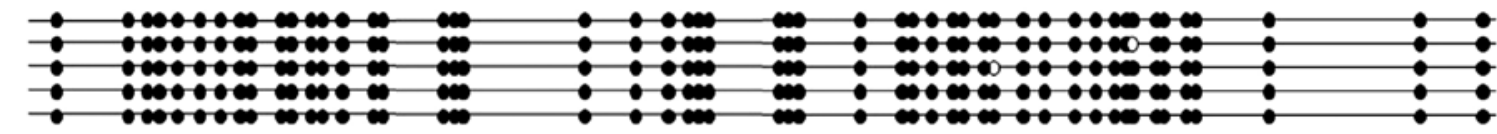

C

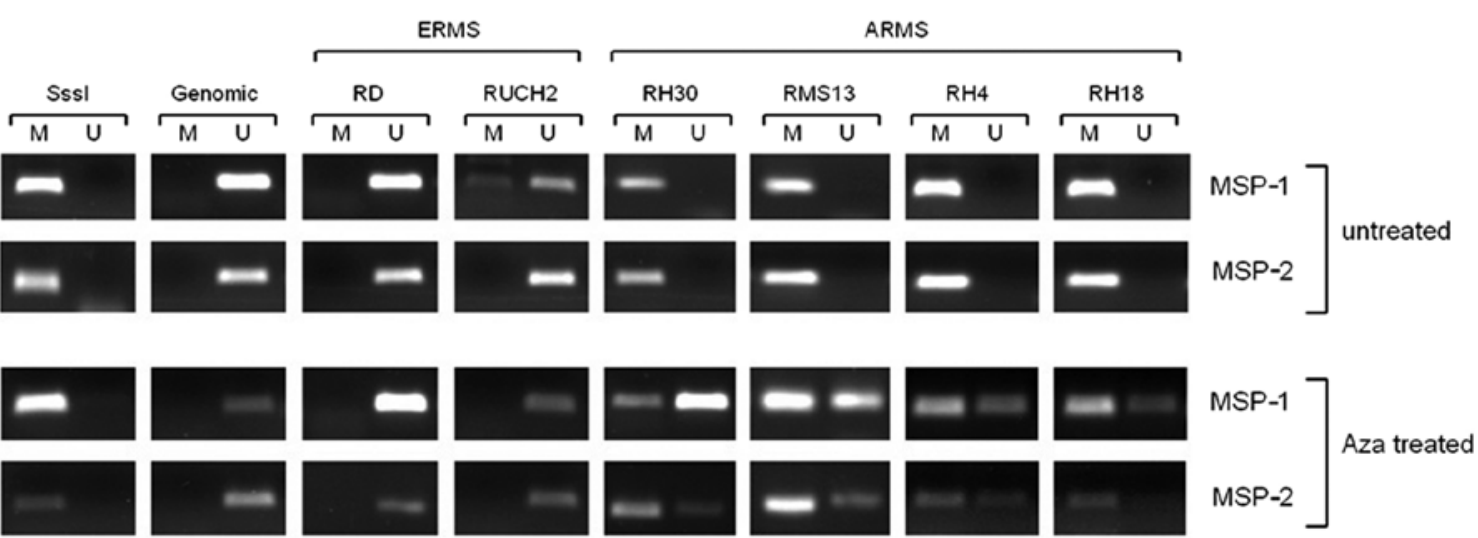

Figure 2. Methylation analyses of the $B M P 2$ promoter region. (A) Schematic drawing of the promoter region ( -270 to +500 bp relative to the transcription start site) of the BMP2 gene showing the distribution of CpGs (vertical lines) within the $\mathrm{CpG}$ island, the location of the primers used for bisulfite sequencing, and the two methylation specific PCRs (MSP-1 and MSP-2). (B) A region of 493 bp including 50 CpG dinucleotides (represented by black and white dots for the methylated and unmethylated state, respectively) was analyzed for DNA methylation by bisulfite sequencing in RD, RMS13 and RH30 cells, with every line representing one single DNA clone. Genomic DNA and SssI-treated DNA served as a negative and positive control for methylated CpGs, respectively. (C) Representative images of MSP-1 and MSP-2 from bisulfite converted DNA of 5-Aza-dC treated and untreated RMS cell lines. M, methylation specific PCR; U, PCR specific for unmethylated CpGs. 

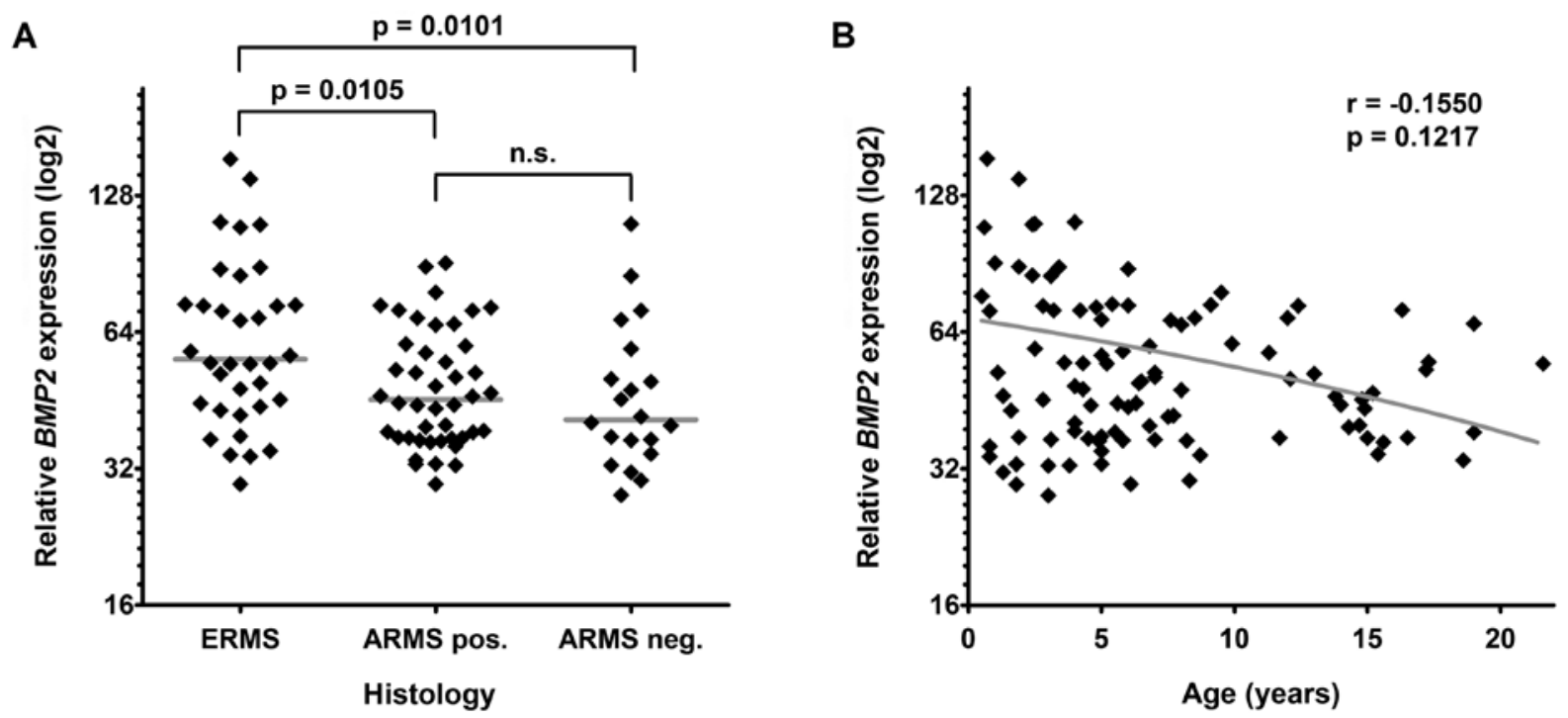

Figure 3. BMP2 expression in human RMS primary samples. (A) Normalized expression of the BMP2 gene in embryonal (ERMS) and translocation-positive and -negative alveolar rhabdomyosarcoma (ARMS), as described in ref. 24. The mean expression values and statistical significances from the unpaired MannWhitney test are given. (B) Relative expression of BMP2 was correlated with the patient age. Statistical significance was calculated using Spearman correlation.

t-test. A level of $\mathrm{p}<0.05$ was considered significant. BMP2 expression values and clinical data of the Williamson and colleagues study (24) were retrieved from the ArrayExpress database (http://www.ebi.ac.uk/arrayexpress/experiments/ETABM-1202/) and analyzed with Mann-Whitney test and Spearman correlation using GraphPad Prism 5.0.

\section{Results}

Identification of BMP2 as an epigenetically silenced gene in RMS cell lines. In a first step, we performed an expression profiling analysis of three RMS tumor cell lines that were treated with the demethylating agent 5-Aza-dC, which should result in the re-expression of epigenetically silenced genes. By using an in-house developed RT-PCR-based assay that simultaneously measures 92 genes implicated in different embryonal signaling pathways, we found 11 genes to be upregulated $\geq 3$-fold in two 5-Aza-dC treated RMS cell lines (GLII, SHH, FOXA2, DKK1, TWIST1, DTX1, IGFBP3, CDH1, IHH, $C D K N 1 C$ and $I G F 1)$. Importantly, strong increased mRNA expression levels of BMP2 (up to 20-fold) and RASSF1A (up to 100-fold) were detected in all treated RMS cell lines (Fig. 1A), the latter confirming earlier results (10). This suggests that $B M P 2$ is epigenetically silenced in RMS.

BMP2 signaling is inactive in RMS cell lines. BMP2 is known to activate a signalling cascade via binding to BMP receptor complexes, which leads to the transcription of the downstream target genes IDI and ID3 (17). As expected from the demethylation experiments, all RMS cell lines expressed very low levels of BMP2 mRNA (Fig. 1B) and protein (Fig. 1C), as compared to normal skeletal muscle. In line with the absence of the BMP2 ligand, transcriptional activity of IDI and ID3 was very low in the RMS cell lines (Fig. 1D and E). By measuring the expression of all three BMP receptor subtypes we could rule out that a lack of receptor expression might be the cause for pathway inactivity (Fig. 1F).
$C p G$ island methylation is present in RMS tumor cell lines. To investigate whether the suppression of the $B M P 2$ gene is caused by DNA hypermethylation, we first screened the $B M P 2$ locus for the occurrence of $\mathrm{CpG}$-islands. We found a $\mathrm{CpG}$-rich region of approximately $500 \mathrm{bp}$ in the 5'-untranslated region of the BMP2 gene, spanning $50 \mathrm{CpG}$-dinucleotides (Fig. 2A). Bisulfite sequencing of this region revealed extremely high methylation rates for the two alveolar RMS cell lines RH30 (97.2\%) and RMS13 (98.0\%) cells, whereas the embryonal RMS cell line RD was less methylated and featured a methylation rate of only $18.4 \%$ (Fig. 2B). In contrast, DNA isolated from peripheral blood displayed no methylation of the whole region under investigation (1.6\%). In vitro methylated DNA (SssI-treated) served as an internal control for detecting full methylation (99.2\%).

In a next step we analyzed if the increase in $B M P 2$ expression upon 5-Aza-dC treatment is associated with DNA demethylation. We therefore performed methylation specific PCR (MSP) of two regions (Fig. 2A), one covering the central part of the $\mathrm{CpG}$ islands screened before by bisulfite sequencing (MSP-2), the other a CpG-rich region in the putative BMP2 promoter region (MSP-1). In untreated cells, MSP assays showed strong methylation of both regions in RH30 and RMS13 cells, whereas RD cells had a band only for the unmethylated state (Fig. 2C). Upon 5-Aza-dC treatment, RH30 and RMS13 cells exhibited bands for both the methylated and the unmethylated state, thereby suggesting demethylation of large proportions of the BMP2 locus. In contrast, the methylation status of 5-Aza-dC treated RD cells remained unchanged (Fig. 2C). As $B M P 2$ promoter methylation was more pronounced in the two alveolar RMS cell lines we performed further MSP analysis before and after 5-Aza-dC treatment using additional RMS cell lines (embryonal, RUCH2; alveolar, RH4 and RH18) and detected a similar pattern (Fig. 2C).

BMP2 expression is preferentially downregulated in alveolar $R M S$. In order to see whether $B M P 2$ expression differs 

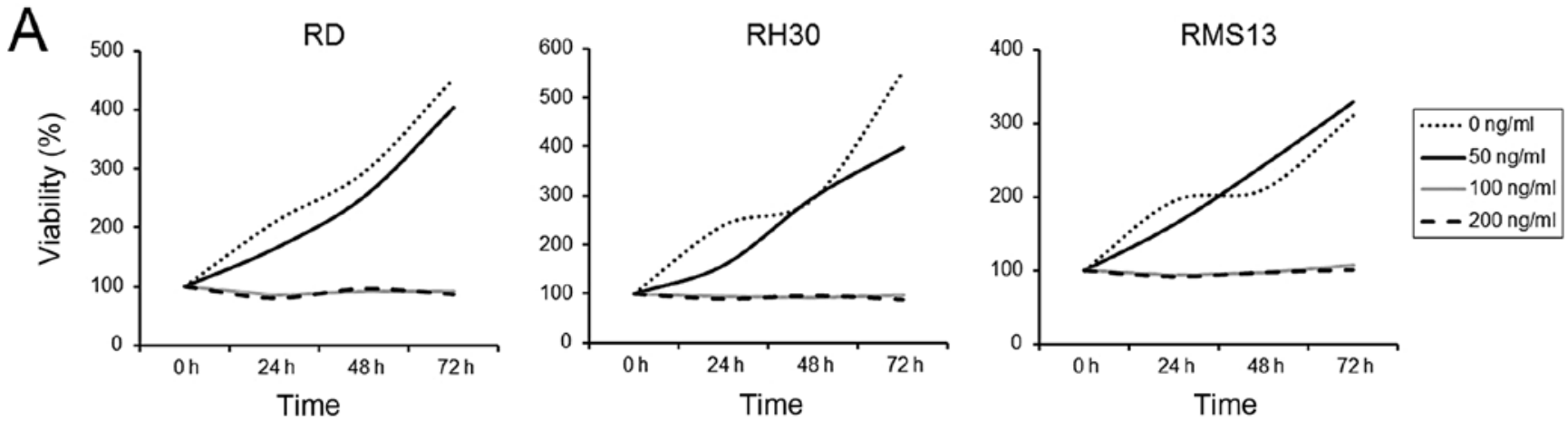

$\mathrm{B}$

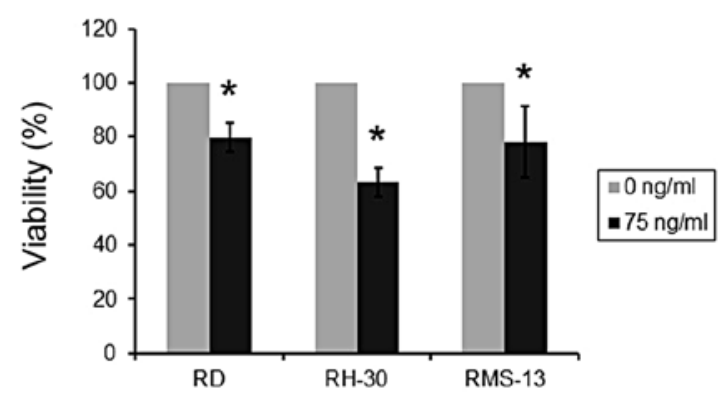

C

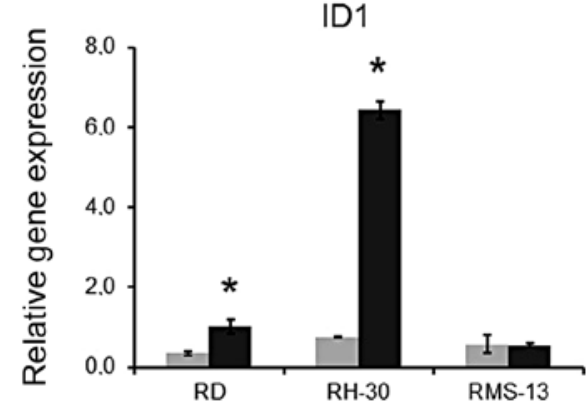

D
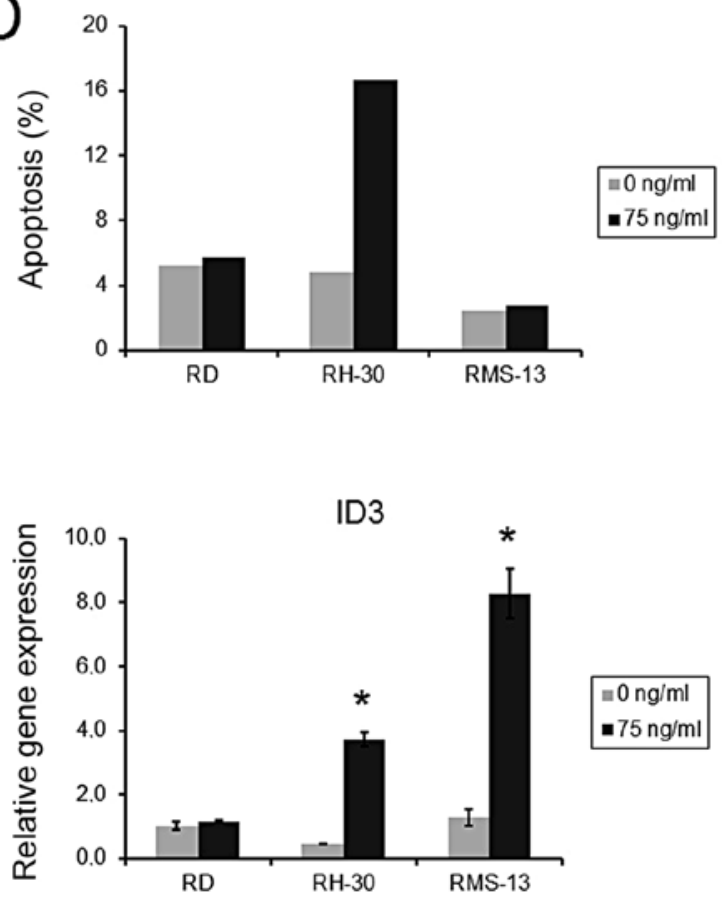

$E$
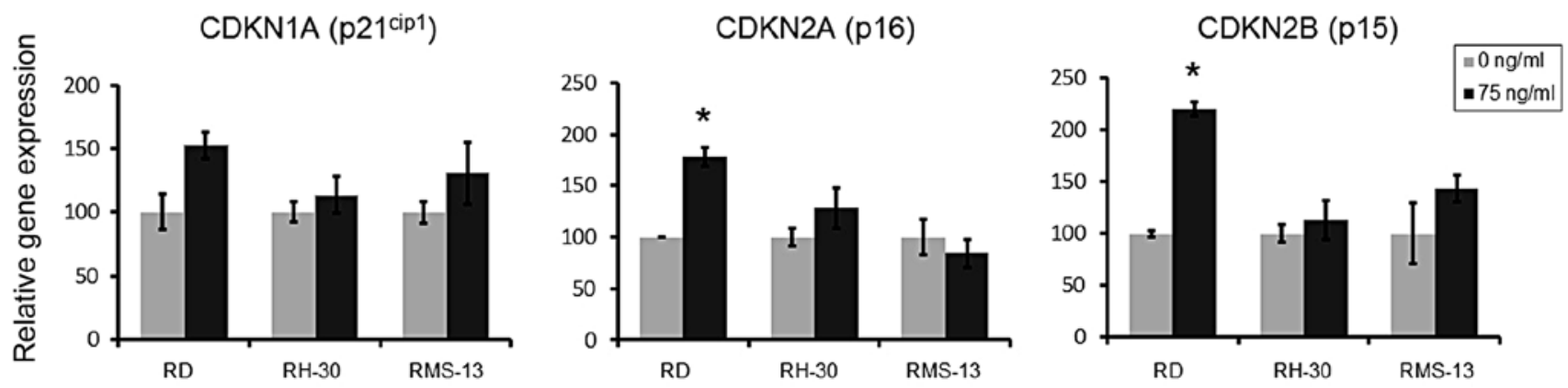

Figure 4. Functional analyses of BMP2 reconstitution. Viability assays of RMS cell lines were performed after treatment with (A) $0,50,100$ and 200 ng/ml rhBMP2 for $0-72 \mathrm{~h}$ as well as (B) $75 \mathrm{ng} / \mathrm{ml} \mathrm{rhBMP} 2$ for $72 \mathrm{~h}$. (C) Relative mRNA expression levels of the target genes $I D 1$ and $I D 3$ in relation to the housekeeping gene TBP. (D) Early apoptotic cells were determined by Annexin V-and calcein-staining after $72 \mathrm{~h}$ of $75 \mathrm{ng} / \mathrm{ml} \mathrm{rhBMP} 2$-treatment. (E) Relative mRNA expression levels of the cell cycle inhibitor genes $C D K N 1 A, C D K N 2 A$ and $C D K N 2 B$ with and without treatment of 75 ng/ml rhBMP2 for $72 \mathrm{~h}$. Bars represent relative candidate gene expression in relation to the housekeeping gene $T B P$. Significant statistical difference versus untreated cells: *Significant with $\mathrm{p}<0.05$ (unpaired Student's t-test).

between the RMS subtypes not only in tumor cell lines but also in primary tissue, we studied the $B M P 2$ mRNA levels in a large cohort of human RMS samples that have previously been analyzed in a microarray-based expression profiling study (25). As expected, we found significantly decreased expression levels of $B M P 2$ in alveolar RMS compared to embryonal RMS (Fig. 3A). However, there was no gross difference between translocation-positive and -negative alveolar 
RMS. In line with the increased age of RMS patients with the alveolar subtype we found a trend towards lower $B M P 2$ expression levels in older patients (Fig. 3B). These data suggest that methylation-dependent $B M P 2$ suppression predominantly occurs in alveolar RMS.

$B M P 2$ reconstitution leads to reduced $R M S$ cell viability. Having shown that $B M P 2$ expression can be reactivated by demethylation, we determined the effects of BMP2 reconstitution in RMS cells by supplementation of recombinant human BMP2 (rhBMP2). Using cell viability as readout, we detected a complete block of proliferation in all three RMS cell lines at doses of 100 and $200 \mathrm{ng} / \mathrm{ml} \mathrm{rhBMP} 2$, an effect that was already amenable after $24 \mathrm{~h}$ (Fig. 4A). In contrast, doses of $\leq 50 \mathrm{ng} / \mathrm{ml}$ rhBMP2 had no effect on RMS cell growth, even after $72 \mathrm{~h}$ of incubation. By choosing an intermediate concentration of $75 \mathrm{ng} / \mathrm{ml} \mathrm{rhBMP} 2$ we found a significantly decreased cell viability of RD, RH30 and RMS13 cells after 72 h, with RH30 being the most sensitive cell line (Fig. 4B). To ensure BMP2 pathway induction by this rhBMP 2 concentration, we checked transcriptional activation of the target genes IDI and ID3 upon treatment. Indeed, significantly induced mRNA expression of at least one of the target genes was found in each cell line, which was most prominent in RH30 cells (Fig. 4C).

Next, we analyzed if reduced cell growth is associated with an enhanced apoptosis. Using $75 \mathrm{ng} / \mathrm{ml} \mathrm{rhBMP} 2$ and Annexin V staining as readout for early apoptosis, we found no significant influence of rhBMP2 treatment on the apoptosis rate at 24 and $48 \mathrm{~h}$ in the three RMS cell lines (data not shown). After $72 \mathrm{~h}$ of treatment, only RH30 cells showed an increase in apoptosis, whereas RD and RMS13 showed no response (Fig. 4D).

To obtain insight into the mechanism of cell proliferation inhibition, we furthermore examined mRNA levels of the growth inhibitor genes $C D K N 1 A, C D K N 2 A$ and $C D K N 2 B$. Treatment of RMS tumor cell lines with $75 \mathrm{ng} / \mathrm{ml} \mathrm{rhBMP} 2$ led to significant upregulation of $C D K N 2 A$ and $C D K N 2 B$ mRNA levels in RD, but not in RH30 and RMS13 cells (Fig. 4E).

Taken together, these results suggest that reconstitution of BMP2 in RMS cells leads to the inhibition of cell proliferation, presumably caused by either the induction of apoptosis (RH30) or cell cycle arrest (RD).

\section{Discussion}

Epigenetic silencing of tumor suppressor genes via $\mathrm{CpG}$ hypermethylation is a well-known phenomenon fostering tumor growth and progression in a variety of cancers $(9,26)$. In RMS, however, very little is known about the epigenetic basis of tumor development. In order to detect epigenetically silenced genes in RMS, we performed an expression profiling analysis of three RMS cell lines treated with the demethylating agent 5-Aza-dC. Besides others, our approach identified two candidate genes, RASSF1A and BMP2, which displayed the most significant transcriptional upregulation in all three cell lines.

RASSF1A has already been shown to be epigenetically silenced in RMS (10). As RASSF1A is thought to act as a tumor suppressor in other tumors including lung, breast, kidney, bladder and ovarian cancer (27-31), it has been suggested that loss of RASSF1A through epigenetic silencing is also critical in RMS development (10). Although this has not yet been proven experimentally, the identification of RASSF1A in our approach at least underscores the reliability of our experimental setup to identify epigenetically silenced genes.

BMP2 has been suggested to be a negative regulator in the growth of skeletal muscle, which can be deduced from the finding that $B M P 2$ overexpression inhibits injury-induced intimal hyperplasia (32). Furthermore, overexpression of the positive regulator of myogenesis follistatin leads to an exorbitant increase of skeletal muscle in mice by neutralizing the inhibitory action of activin, myostatin and BMP2 $(33,34)$. In line with this, BMP2 expression was very high in fully differentiated normal muscle tissue, both on the mRNA and protein level, whereas the levels in all RMS cell lines were significantly low. Besides the impaired $B M P 2$ expression it has been reported that the BMP2/SMAD pathway itself could be defective and contributes to tumor growth, as described for colon cancer $(35,36)$. By detecting all three BMP-receptor components (BMPR1A, BMPR1B and BMPR2) in RMS and in normal muscle tissue as well as by revealing the induction of the target genes IDI and ID3 after rhBMP2 treatment we could avert the suspicion that an impaired BMP2/SMAD pathway might be the reason for non-activated BMP2 signaling.

Interestingly, $B M P 2$ expression in RMS was increased after 5-Aza-dC treatment to levels found in healthy muscle tissue. These results suggested that DNA methylation might be the major cause of BMP2 suppression in RMS cells, a scenario that has earlier been described in gastric cancer (37). Indeed, using bisulfite sequencing of a $\mathrm{CpG}$-island located in the promoter region of $B M P 2$, we found an almost complete methylation of all $\mathrm{CpG}$-dinucleotides in the two investigated alveolar RMS cell lines, whereas the embryonal RMS cell line RD showed a distinct methylation of $\sim 20 \%$. In clear contrast is the methylation pattern of DNA isolated from whole blood, which was completely unmethylated. These findings were verified by methylation specific PCR, also in additional RMS cell lines. Furthermore, significantly lower BMP2 expression levels in primary ARMS compared to ERMS together with the differential methylation patterns in alveolar compared to embryonal RMS cell lines strengthen previous findings of diverse methylation patterns in RMS subtypes (38). Therefore, the mechanism of gene silencing via promoter hypermethylation, which is well known from a variety of different cancers $(9,26,39,40)$, can also be anticipated of being important in RMS. In view of only moderate methylation patterns in the embryonal RMS cell line, there may also be mechanisms other than promoter hypermethylation causing $B M P 2$ silencing. Accordingly, it has been shown that the transcription of $B M P 2$ in osteoblasts is regulated via enhancers, regulatory DNA elements located far upstream of the promoter $(41,42)$. Thus, methylation of these elements or other unknown regions at the $B M P 2$ locus not covered by our assays may be responsible for BMP2 silencing.

In order to illuminate whether demethylation is the cause of BMP2 reexpression after 5-Aza-dC treatment, we determined the methylation pattern in treated RMS cell lines. However, the assumed demethylating effect of 5-Aza-dC causing the re-expression was only obvious in the two RMS cell lines showing strong $\mathrm{CpG}$ methylation, although all three cell 
lines showed a significant reactivation of $B M P 2$ gene expression after treatment. This discrepancy could be explained by the finding that 5 -Aza-dC is known of being a relatively unspecific agent, which can also change histone modifications which might be important in the transcriptional regulation of BMP2 in RD cells. Furthermore, 5-Aza-dC leads to global demethylation and thereby transcriptional regulation of many different genes $(43,44)$. In colon cancer it has been shown that 5-Aza-dC rather led to global demethylation than specific demethylation in CpG-rich promoter regions, which results in a strong gene re-expression (45). Similar results have been described for the $C D H 1$ gene in malignant liver tumors (46). Thus, it can be suggested that not only strong demethylation in promoter regions can cause re-expression of genes, but also demethylation on distant parts of the gene. In addition, histone modifications or methylation of other parts of the BMP2 promoter, which were not included in our analysis, could be responsible for changes in $B M P 2$ expression.

In a variety of tumors with loss of $B M P 2$ expression, e.g., medulloblastoma (22), gastric, breast, colon and prostatic cancer (19,36,37,47-49), the reconstitution of BMP2 resulted in reduced tumor proliferation. In addition, research on smooth muscle cells, whose growth were restricted by rhBMP2 and $B M P 2$ gene transfer $(32,50)$, gave reason to expect a similar function in RMS. After having proved the induction of the BMP2 pathway in RMS cells upon rhBMP2 treatment by the transcriptional activation of the well-known BMP2 target genes IDI and ID3 $(18,51,52)$, we could show that rhBMP2 treatment significantly reduced RMS cell proliferation in all cell lines in a dose-dependent manner, thereby suggesting that $B M P 2$ acts as a tumor suppressor gene by the inhibition of RMS tumor growth.

The ability of rhBMP2 to reduce proliferation has been already ascribed to a raised G1-arrest with consecutive apoptosis, as described for myeloma cells (21). Moreover, smooth muscle cells have been reported to react on BMP2 by reduced proliferation and increased apoptosis (53). Nevertheless, there are also reports of cell protective effects, such as a reduced apoptosis rate in neuroectodermal cells (54). Accordingly, the BMP2 function on apoptosis seems to be tissue- or at least cell type-dependent. Our apoptosis analysis on BMP2-treated RMS cells only detected an enhanced apoptosis rate in one of three cell lines (RH30), despite reduced proliferation in all RMS cell lines. In order to illuminate this divergence between proliferation and apoptosis, we examined mRNA levels of CDKN1A (p21), CDKN2A (p16) and CDKN2B (p15), important genes for the control of the cell cycle and the G1-phase (55). CDKN1A has been described earlier to be activated via rhBMP2 treatment in gastric cancer and smooth muscle leading to reduced cell proliferation $(49,50)$. However, a significant increase of these genes after rhBMP2 treatment was only detected in one cell line (RD). Thus, we assume that the inhibition of proliferation through BMP2 is not due to a single mechanism, but rather that cell cycle-arrest and in addition the induction of apoptosis are relevant, which has to be addressed in future experiments.

Collectively, our study shows that $B M P 2$ is silenced in RMS via promoter hypermethylation and that the reconstitution of BMP2 significantly decreases tumor cell proliferation. However, the underlying molecular mechanisms for the growth suppressive effect of BMP2 are not entirely clear, as the induction of apoptosis or cell cycle-inhibitory genes is not evident in all RMS cell lines. Nevertheless, our data warrant further investigations on the use of BMP2 reconstitution for therapeutic purposes in RMS.

\section{Acknowledgements}

We are grateful to Fatemeh Promoli, Anett Domokos, and Nicole Stadler for technical assistance. Dr Beat Schäfer (University of Zurich, Switzerland) provided the RMS cell lines. This study was supported by the FöFoLe program 'Molecular Medicine' of the Medical Faculty of the LudwigMaximilians University of Munich.

\section{References}

1. Paulino AC and Okcu MF: Rhabdomyosarcoma. Curr Probl Cancer 32: 7-34, 2008.

2. Crist W, Gehan EA, Ragab AH, Dickman PS, Donaldson SS, Fryer C, Hammond D, Hays DM, Herrmann J, Heyn R, et al: The Third Intergroup Rhabdomyosarcoma Study. J Clin Oncol 13: 610-630, 1995.

3. Meyer WH and Spunt SL: Soft tissue sarcomas of childhood. Cancer Treat Rev 30: 269-280, 2004.

4. Newton WA Jr, Soule EH, Hamoudi AB, Reiman HM, Shimada H, Beltangady M and Maurer H: Histopathology of childhood sarcomas, Intergroup Rhabdomyosarcoma Studies I and II: clinicopathologic correlation. J Clin Oncol 6: 67-75, 1988.

5. Sorensen PH, Lynch JC, Qualman SJ, Tirabosco R, Lim JF, Maurer HM, Bridge JA, Crist WM, Triche TJ and Barr FG: PAX3-FKHR and PAX7-FKHR gene fusions are prognostic indicators in alveolar rhabdomyosarcoma: a report from the children's oncology group. J Clin Oncol 20: 2672-2679, 2002

6. Loh WE Jr, Scrable HJ, Livanos E, Arboleda MJ, Cavenee WK, Oshimura $\mathrm{M}$ and Weissman BE: Human chromosome 11 contains two different growth suppressor genes for embryonal rhabdomyosarcoma. Proc Natl Acad Sci USA 89: 1755-1759, 1992.

7. Barr FG: Gene fusions involving PAX and FOX family members in alveolar rhabdomyosarcoma. Oncogene 20: 5736-5746, 2001.

8. Fredericks WJ, Galili N, Mukhopadhyay S, Rovera G, Bennicelli J, Barr FG and Rauscher FJ III: The PAX3-FKHR fusion protein created by the $\mathrm{t}(2 ; 13)$ translocation in alveolar rhabdomyosarcomas is a more potent transcriptional activator than PAX3. Mol Cell Biol 15: 1522-1535, 1995.

9. Herman JG and Baylin SB: Gene silencing in cancer in association with promoter hypermethylation. N Engl J Med 349: 2042-2054, 2003.

10. Harada K, Toyooka S, Maitra A, Maruyama R, Toyooka KO, Timmons CF, Tomlinson GE, Mastrangelo D, Hay RJ, Minna JD and Gazdar AF: Aberrant promoter methylation and silencing of the RASSF1A gene in pediatric tumors and cell lines. Oncogene 21: 4345-4349, 2002.

11. Wong IH, Chan J, Wong J and Tam PK: Ubiquitous aberrant RASSF1A promoter methylation in childhood neoplasia. Clin Cancer Res 10: 994-1002, 2004.

12. Sugawara W, Haruta M, Sasaki F, Watanabe N, Tsunematsu Y, Kikuta A and Kaneko Y: Promoter hypermethylation of the RASSF1A gene predicts the poor outcome of patients with hepatoblastoma. Pediatr Blood Cancer 49: 240-249, 2007.

13. Wozney JM, Rosen V, Celeste AJ, Mitsock LM, Whitters MJ, Kriz RW, Hewick RM and Wang EA: Novel regulators of bone formation: molecular clones and activities. Science 242: 1528-1534, 1988.

14. Lyons KM, Hogan BL and Robertson EJ: Colocalization of BMP 7 and BMP 2 RNAs suggests that these factors cooperatively mediate tissue interactions during murine development. Mech Dev 50: 71-83, 1995.

15. Duprez DM, Coltey M, Amthor H, Brickell PM and Tickle C: Bone morphogenetic protein-2 (BMP-2) inhibits muscle development and promotes cartilage formation in chick limb bud cultures. Dev Biol 174: 448-452, 1996. 
16. Narita T, Saitoh K, Kameda T, Kuroiwa A, Mizutani M, Koike C, Iba $\mathrm{H}$ and Yasugi S: BMPs are necessary for stomach gland formation in the chicken embryo: a study using virally induced BMP-2 and Noggin expression. Development 127: 981-988, 2000.

17. Chen D, Zhao M and Mundy GR: Bone morphogenetic proteins. Growth Factors 22: 233-241, 2004.

18. Hollnagel A, Oehlmann V, Heymer J, Ruther U and Nordheim A: Id genes are direct targets of bone morphogenetic protein induction in embryonic stem cells. J Biol Chem 274: 19838-19845, 1999.

19. Horvath LG, Henshall SM, Kench JG, Turner JJ, Golovsky D Brenner PC, O'Neill GF, Kooner R, Stricker PD, Grygiel JJ and Sutherland RL: Loss of BMP2, Smad8, and Smad4 expression in prostate cancer progression. Prostate 59: 234-242, 2004.

20. Soda H, Raymond E, Sharma S, Lawrence R, Cerna C, Gomez L, Timony GA, Von Hoff DD and Izbicka E: Antiproliferative effects of recombinant human bone morphogenetic protein-2 on human tumor colony-forming units. Anticancer Drugs 9: 327-331, 1998.

21. Kawamura C, Kizaki M and Ikeda Y: Bone morphogenetic protein (BMP)-2 induces apoptosis in human myeloma cells Leuk Lymphoma 43: 635-639, 2002.

22. Zhao H, Ayrault O, Zindy F, Kim JH and Roussel MF: Posttranscriptional down-regulation of Atoh1/Math1 by bone morphogenic proteins suppresses medulloblastoma development. Genes Dev 22: 722-727, 2008.

23. Pfaffl MW: A new mathematical model for relative quantification in real-time RT-PCR. Nucleic Acids Res 29: e45, 2001.

24. Williamson D, Missiaglia E, de Reynies A, Pierron G, Thuille B, Palenzuela G, Thway K, Orbach D, Lae M, Freneaux P, Pritchard-Jones K, Oberlin O, Shipley J and Delattre O: Fusion gene-negative alveolar rhabdomyosarcoma is clinically and molecularly indistinguishable from embryonal rhabdomyosarcoma. J Clin Oncol 28: 2151-2158, 2010

25. Missiaglia E, Dalai I, Barbi S, Beghelli S, Falconi M, della Peruta M, Piemonti L, Capurso G, Di Florio A, delle Fave G, Pederzoli P, Croce CM and Scarpa A: Pancreatic endocrine tumors: expression profiling evidences a role for AKT-mTOR pathway. J Clin Oncol 28: 245-55, 2010.

26. Esteller M: Epigenetic gene silencing in cancer: the DNA hypermethylome. Hum Mol Genet 16 Spec No 1: R50-R59, 2007.

27. Burbee DG, Forgacs E, Zochbauer-Muller S, Shivakumar L, Fong K, Gao B, Randle D, Kondo M, Virmani A, Bader S Sekido Y, Latif F, Milchgrub S, Toyooka S, Gazdar AF, Lerman MI, Zabarovsky E, White M and Minna JD: Epigenetic inactivation of RASSF1A in lung and breast cancers and malignant phenotype suppression. J Natl Cancer Inst 93: 691-699, 2001 .

28. Dammann R, Li C, Yoon JH, Chin PL, Bates S and Pfeifer GP: Epigenetic inactivation of a RAS association domain family protein from the lung tumour suppressor locus 3p21.3. Nat Genet 25: 315-319, 2000 .

29. Morrissey C, Martinez A, Zatyka M, Agathanggelou A, Honorio S, Astuti D, Morgan NV, Moch H, Richards FM, Kishida T, Yao M, Schraml P, Latif F and Maher ER: Epigenetic inactivation of the RASSF1A 3p21.3 tumor suppressor gene in both clear cell and papillary renal cell carcinoma. Cancer Res 61: 7277-7281, 2001

30. Yoon JH, Dammann R and Pfeifer GP: Hypermethylation of the CpG island of the RASSF1A gene in ovarian and renal cell carcinomas. Int J Cancer 94: 212-217, 2001.

31. Dammann R, Yang G and Pfeifer GP: Hypermethylation of the cpG island of Ras association domain family 1A (RASSF1A), a putative tumor suppressor gene from the 3 p21.3 locus, occurs in a large percentage of human breast cancers. Cancer Res 61: 3105-3109, 2001

32. Nakaoka T, Gonda K, Ogita T, Otawara-Hamamoto Y, Okabe F, Kira Y, Harii K, Miyazono K, Takuwa Y and Fujita T: Inhibition of rat vascular smooth muscle proliferation in vitro and in vivo by bone morphogenetic protein-2. J Clin Invest 100: 2824-2432, 1997.

33. Lee SJ and McPherron AC: Regulation of myostatin activity and muscle growth. Proc Natl Acad Sci USA 98: 9306-9311, 2001.

34. Suryawan A, Frank JW, Nguyen HV and Davis TA: Expression of the TGF-beta family of ligands is developmentally regulated in skeletal muscle of neonatal rats. Pediatr Res 59: 175-179, 2006 .
35. Howe JR, Bair JL, Sayed MG, Anderson ME, Mitros FA, Petersen GM, Velculescu VE, Traverso G and Vogelstein B: Germline mutations of the gene encoding bone morphogenetic protein receptor 1A in juvenile polyposis. Nat Genet 28: 184-187, 2001.

36. Kodach LL, Wiercinska E, de Miranda NF, Bleuming SA, Musler AR, Peppelenbosch MP, Dekker E, van den Brink GR, van Noesel CJ, Morreau H, Hommes DW, Ten Dijke P, Offerhaus GJ and Hardwick JC: The bone morphogenetic protein pathway is inactivated in the majority of sporadic colorectal cancers. Gastroenterology 134: 1332-1341, 2008.

37. Wen XZ, Akiyama Y, Baylin SB and Yuasa Y: Frequent epigenetic silencing of the bone morphogenetic protein 2 gene through methylation in gastric carcinomas. Oncogene 25: 2666-2673, 2006.

38. Mahoney SE, Yao Z, Keyes CC, Tapscott SJ and Diede SJ: Genome-wide DNA methylation studies suggest distinct DNA methylation patterns in pediatric embryonal and alveolar rhabdomyosarcomas. Epigenetics 7: 400-408, 2012.

39. Bird A: DNA methylation patterns and epigenetic memory. Genes Dev 16: 6-21, 2002.

40. Esteller M: Cancer epigenomics: DNA methylomes and histonemodification maps. Nat Rev Genet 8: 286-298, 2007.

41. Pregizer S and Mortlock DP: Control of BMP gene expression by long-range regulatory elements. Cytokine Growth Factor Rev 20: 509-515, 2009 .

42. Chandler RL, Chandler KJ, McFarland KA and Mortlock DP: Bmp2 transcription in osteoblast progenitors is regulated by a distant 3' enhancer located 156.3 kilobases from the promoter. Mol Cell Biol 27: 2934-2951, 2007.

43. Jabbour E, Issa JP, Garcia-Manero G and Kantarjian H: Evolution of decitabine development: accomplishments, ongoing investigations, and future strategies. Cancer 112: 2341-2351, 2008.

44. Cameron EE, Bachman KE, Myohanen S, Herman JG and Baylin SB: Synergy of demethylation and histone deacetylase inhibition in the re-expression of genes silenced in cancer. Nat Genet 21: 103-107, 1999.

45. Mossman D, Kim KT and Scott RJ: Demethylation by 5-aza2'-deoxycytidine in colorectal cancer cells targets genomic DNA whilst promoter $\mathrm{CpG}$ island methylation persists. BMC Cancer 10: 366,2010

46. Tachibana K, Takeda K and Shiraishi M.: 5-Aza-2'-deoxycytidine reactivates the $\mathrm{CDH} 1$ gene without influencing the methylation of the entire $\mathrm{CpG}$ island or histone modification in a human cancer cell line. Proc Japan Acad 80: 342-348, 2004.

47. Ghosh-Choudhury N, Woodruff K, Qi W, Celeste A, Abboud SL and Ghosh Choudhury G: Bone morphogenetic protein-2 blocks MDA MB 231 human breast cancer cell proliferation by inhibiting cyclin-dependent kinase-mediated retinoblastoma protein phosphorylation. Biochem Biophys Res Commun 272: 705-711, 2000.

48. Beck SE, Jung BH, Fiorino A, Gomez J, Rosario ED, Cabrera BL, Huang SC, Chow JY and Carethers JM: Bone morphogenetic protein signaling and growth suppression in colon cancer. Am J Physiol Gastrointest Liver Physiol 291: G135-G145, 2006.

49. Wen XZ, Miyake S, Akiyama Y and Yuasa Y: BMP-2 modulates the proliferation and differentiation of normal and cancerous gastric cells. Biochem Biophys Res Commun 316: 100-106, 2004.

50. Wong GA, Tang V, El-Sabeawy F and Weiss RH: BMP-2 inhibits proliferation of human aortic smooth muscle cells via $\mathrm{p} 21^{\text {Cipl/Waf1 }}$ Am J Physiol Endocrinol Metab 284: E972-E979, 2003

51. Du Y and Yip H: Effects of bone morphogenetic protein 2 on Id expression and neuroblastoma cell differentiation. Differentiation 79: 84-92, 2010.

52. Ogata T, Wozney JM, Benezra R and Noda M: Bone morphogenetic protein 2 transiently enhances expression of a gene, Id (inhibitor of differentiation), encoding a helix-loop-helix molecule in osteoblast-like cells. Proc Natl Acad Sci USA 90: 9219-9222, 1993.

53. Zhang S, Fantozzi I, Tigno DD, Yi ES, Platoshyn O, Thistlethwaite PA, Kriett JM, Yung G, Rubin LJ and Yuan JX: Bone morphogenetic proteins induce apoptosis in human pulmonary vascular smooth muscle cells. Am J Physiol Lung Cell Mol Physiol 285: L740-L754, 2003.

54. Iantosca MR, McPherson CE, Ho SY and Maxwell GD: Bone morphogenetic proteins-2 and -4 attenuate apoptosis in a cerebellar primitive neuroectodermal tumor cell line. J Neurosci Res 56: 248-258, 1999.

55. Sherr CJ and Roberts JM: CDK inhibitors: positive and negative regulators of G1-phase progression. Genes Dev 13: 1501-1512, 1999. 